\title{
Application of community-based nutrition education needs assessment in reviewing the course plan of medical and nursing students
}

\author{
Sahar Golabi ${ }^{1}$, Mitra Amini ${ }^{2}$, Atefeh Zahedi ${ }^{3}$, Maryam Adelipour ${ }^{4}$, Zahra Shamekhi ${ }^{5}$, Leila Fakharzadeh ${ }^{1}$, \\ Samaneh Mansouri ${ }^{1}$, Mahshid Naghashpour ${ }^{1 * \mathbb{D}}$
}

Received: 12 Jul 2020

Published: 21 Jun 2021

\section{Abstract}

Background: Training needs assessment is the process of recognizing educational needs. This study aimed to apply a communitybased nutrition education needs assessment to revise the nutrition course plan in the curriculum of the doctorate of medicine and that of the baccalaureate of nursing.

Methods: The study was designed in 2 phases: (1) nutritional needs assessment; (2) community-based revision of nutrition course plan. In the first phase, 13 nutrition professionals working in the region set out 5 priorities of nutrition-related health problems in the community by a training need assessment based on a survey and scoring system. Then, an expert panel determined the priorities of behavioral and nonbehavioral causes of the nutrition-related health problems by the nominal group technique (NGT). The results of the first phase were used to review the topics of nutrition course plans up to $20 \%$.

Results: The priorities identified in Abadan, Khorramshahr, and Shadegan were obesity and type 2 diabetes mellitus in adults as well as anemia in pregnant women, respectively. Also, wrong eating habits and insufficient nutrition knowledge were among the most important behavioral causes of nutrition-related health problems in the target community. These results were applied to a communitybased review of nutrition course plans for medical and nursing students.

Conclusion: The use of nutritional needs assessment approaches by a survey and nominal group technique with a group of professionals provided an opportunity for a community-based review of the nutrition course plan for medical and nursing students as a first phase in the development of a community-based nutrition course plane.

Keywords: Community, Course Plan, Educational Content, Nutrition-Related Health Problems

Conflicts of Interest: None declared

Funding: This project was funded by the Vice-Chancellor in Research Affairs, Abadan Faculty of Medical Sciences, Abadan, Iran (gramt code: 96U-231).

\section{*This work has been published under CC BY-NC-SA 1.0 license.}

Copyright $\odot$ Iran University of Medical Sciences

Cite this article as: Golabi S, Amini M, Zahedi A, Adelipour M, Shamekhi Z, Fakharzadeh L, Mansouri S, NaghashpourM. Application of community-based nutrition education needs assessment in reviewing the course plan of medical and nursing studenits. Med J Islam Repub Iran. 2021 (21 Jun);35:80. https://doi.org/10.47176/mjiri.35.80

\section{Introduction}

Need is the "gap" between current and desired conditions

Corresponding author: Dr Mahshid Naghashpour, m.naghashpour@abadanums.ac.ir

1. Abadan Faculty of Medical Sciences, Abadan, Iran

2. Clinical Education Research Center, Shiraz University of Medical Sciences, Shiraz, Iran

3. Asadabad School of Medical Sciences, Asadabad, Iran

4. Department of Biochemistry, Faculty of Medicine, Ahvaz Jundishapur University of Medical Sciences, Ahvaz, Iran

5. Sepidan Bagherololoom Higher Education college, Shiraz University of Medical Sciences, Shiraz, Iran or "wants." The disparity between the current and wanted

$\uparrow$ What is "already known" in this topic:

Training needs assessment is an essential basis for designing a curriculum development and review. Indeed, community needs and learner needs overlap. In addition, the most medical schools do not deliver applicable nutrition education, and their graduates do not have the necessary nutritional skills in medicine. Also, medical students felt that the nutrition counselling of their patients is unsatisfactory.

$\rightarrow$ What this article adds:

The aim of this study was to demonstrate the ability to use community-based nutritional needs assessment techniques to determine nutrition-related health problems in the community to provide a prospect for a community-based review of the nutrition course plan for medical and nursing students as a first phase in the development of a course plane. 
conditions must be measured to identify the need appropriately (1). A needs assessment is a part of planning processes, often used for improvement in education/training (2). Training needs assessment (TNA) is the introduction of the educational goal selection and an essential foundation for designing and setting a curriculum program and its elements. TNA is the process of identifying educational needs leading the training to help achieve the organizational goals. Moreover, TNA makes the necessary changes in the behavior of learners and creates critical abilities in the individuals and the society $(3,4)$. Most organizations develop and implement education without studying and analyzing needs. These organizations are at risk of being overtrained, less trained, or wholly abandoned (3). TNA results allow the administrator to set up educational goals based on the answers to 2 fundamental questions: Who needs education? What training is needed? (5).

One of the educational goals is to meet the society's needs. Although TNA is done to determine educational goals based on learner and community resources, in many cases, the learner's need is considered to be the community's need. On the other hand, learner needs and community needs overlap. A needs assessment based on a survey is a way of asking the group or community members what their most important needs are (6).

Studies show that the results of the TNA can be used to design students' educational curriculum, leading to the promotion of adequate health care by them in the social context of the workplace setting (7). Our research is within the constructivists' research pattern. In constructivism, knowledge is socially created and realities are made by the interaction of interpersonal, cultural, and social factors. Therefore, there are multiple accounts of realities, and meaning is understood through mutual interactions between the researcher and participants and the context of the research. Accordingly, the delivery of nutrition care by a physician/nurse is a behavior established in the social context of the workplace settings. Contextual factors, which may influence nutrition education, are lack of priority for nutrition, lack of faculty to provide nutrition education, poor integration of nutrition as a theme throughout the curriculum, and already overcrowded curriculum (8).

Reports have emphasized the need to reform medical education to bring it into an agreement with social needs and expectations (9).

Historically, less attention has been paid to nutrition sciences in the curriculums of many medical schools. In 1985, the National Academy of Sciences of the United States published an essential report on nutrition education in medical faculties (10). The results showed that most medical schools in the United States did not provide proper nutrition education and did not produce graduates with the necessary nutritional skills in medicine. Studies focusing on undergraduate and graduate medical students in the United States found that they feel the nutrition counselling of their patients is unsatisfactory. The findings also show that physicians, especially early in their careers, do not have much confidence in the necessary knowledge or skills to counsel and motivate their patients to follow a healthy diet and lifestyle (1113).
In this study, the priorities of nutrition-related health problems in Abadan, Khorramshahr, and Shadegan in Southwest of Iran have been determined to review the nutrition course plan at the meso level based on the community needs.

\section{Methods}

\section{Ethics}

This project was approved by the ethics committee of the vice-chancellor in Research Affairs, Abadan Faculty of Medical Sciences, Abadan, Iran (Code: IR.ABADANUMS.REC.1398.052). Students participated in the study voluntarily and their names were not revealed in the written forms. Written informed consent for participation in the study was obtained before formal acceptance to participate.

\section{Study Design}

This was a 2-phase qualitative study conducted in Abadan Faculty of Medical Sciences in 2017-2019. Abadan Faculty of Medical Sciences covers the communication of 3 cities and their suburbs, including Abadan, Khorramshahr, and Shadegan, in the Khuzestan province, in the Southwest of Iran in terms of medical education and health care. Moreover, this faculty is located in the fourth educational spatial region from the 10 educational spatial areas of the Ministry of Health and Medical Education, the executive branch responsible for medical education and health within the Iranian government. Ten areas of spatial planning show the geographical breakdown of medical universities in Iran, which is approved in the form of a resolution by the Council of the Cultural Revolution as a macropolicy maker of science and technology in Iran (14).

\section{Adequate Sample Size}

The sample size was characterized based on the principles mentioned in the Vasileiou's study (15). In this study we included the whole community of nutrition experts working in the public and private sectors of the cities where the research was conducted. Invited individuals who desired to participate in the study attended the sessions.

This phase was completed in 2 phases:

\section{Phase 1: Nutritional Needs Assessment}

In the first phase, 13 nutrition professionals $(70 \% \mathrm{fe}-$ males), with a mean age of $33 \pm 1$ years and the duration of work experience of $6.5 \pm 2.3$ y'ears working in the governmental and the private nutrition care services of Abadan, Khorramshahr, and Shadegan, were included in the study. They had practiced in the field of nutrition and had an indepth knowledge about the nutrition-related health problems of the community. Nutrition professionals provided the services to the community, including evaluating the nutrition needs of individuals and groups and determining priorities, goals, and objectives to meet nutrition needs as well as the resources and restrictions in the practice setting (16). They were invited to participate in the study by sending an official invitation letter from the university's deputy educational director. They completed worksheets developed by high- 
level policymakers of Iran's Ministry of Health and Medical Education for an Iranian community-based assessment. Each nutrition professional was asked to record the first 10 nutrition-related health problems observed in the city of her/his workplace. A nutrition-related health problem was a nutrition problem that directly threatens people's health. The resources and examples used to identify the problem were also listed in front of each of the problems. Then, all nutrition professionals scored the listed nutrition-related health problems from 1 to 5 . This ranking was based on the extent of the problem, the possibility of intervention, the effectiveness of education in solving the problem, the urgency of the problem, and the social and organizational acceptability of problem-solving. The scores were selected according to the following qualitative criteria: very low $=1$, low $=2$, average $=3$, high $=4$, and very high $=5$. The scores gave to each problem was summed up to obtain a total score for each problem. Finally, 5 problems with the most obtained score were declared as priorities for the nutrition-related health problems (17).

In the second phase, an expert panel was assembled that consisted of 9 professionals in different fields, including health, nutrition, medicine, nursing, and epidemiology, and convened through an official invitation letter. The participants were academics and clinicians who had been involved in clinical and health services related to aspects of health (n $=3)$, nutrition $(n=1)$, medical care of community $(n=3)$, nursing $(\mathrm{n}=1)$, and epidemiology $(\mathrm{n}=1)$ (Fig. 1).

In this panel, the nominal group technique (NGT) (18) was used to identify a preliminary list of causes of each nutrition-related health problem in the region and categorize them into "behavioral" and "nonbehavioral" types. NGT in this project lasted approximately 4 hours and was facilitated by the researcher. Following a description of the process, group purposes with a statement of the importance of participant's contribution, clarification of the members' roles, and an explanation about how the group's output would be used, the NGT session was conducted in 5 steps (19). In the NGT process, a researcher (SM) recorded the voice and described it and other researchers ( $\mathrm{SG}$ and $\mathrm{MN}$ ) checked her description and data analysis.

\section{Step 1: Silent Generation of Causes Priorities}

Participants were asked to take 15 minutes to consider the following question: "What are the priorities of the behavioral and nonbehavioral causes of nutrition-related health prob-

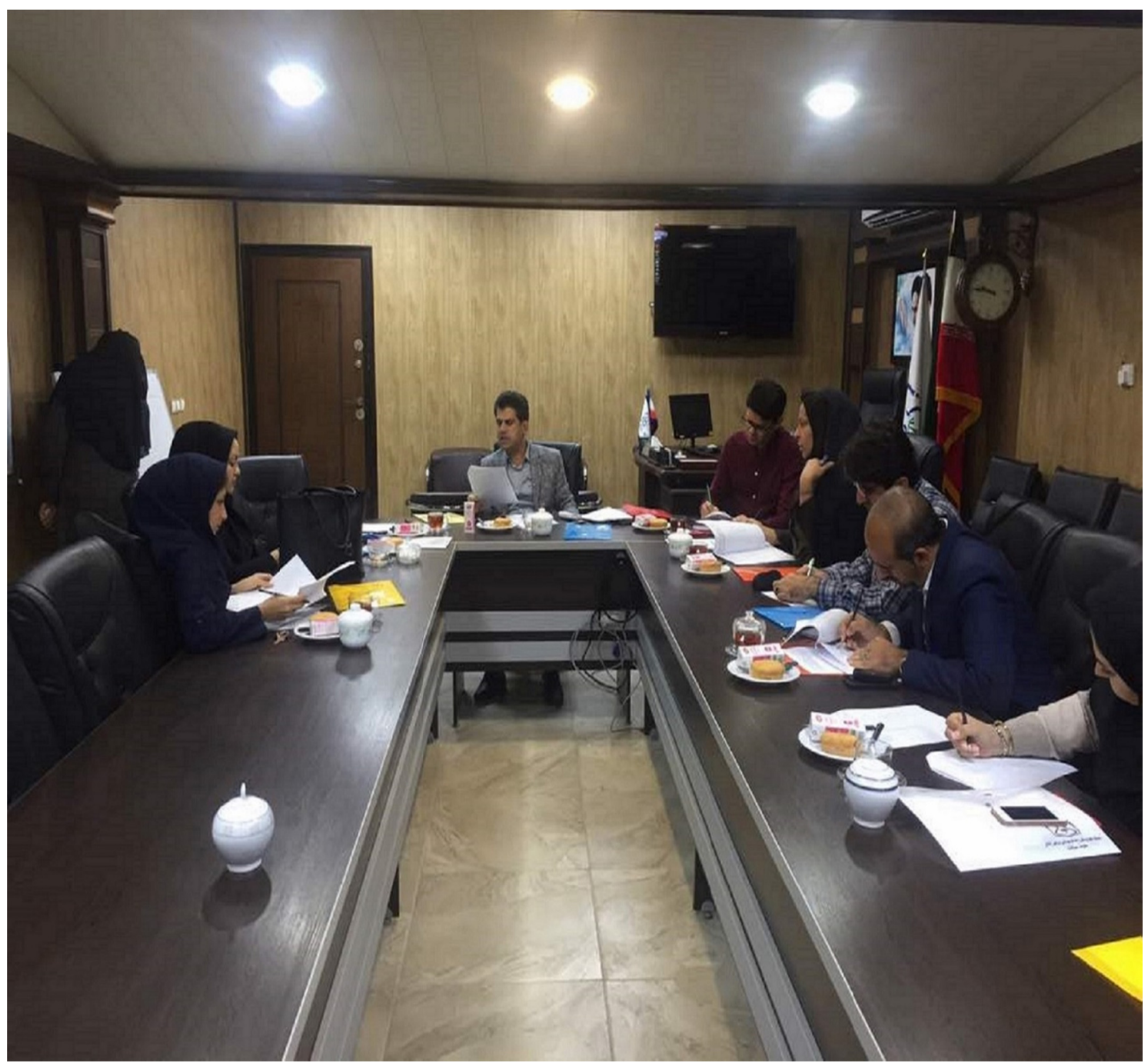

Fig. 1. The expert panel at vice chancellor in Health, Abadan Faculty of Medical Sciences; the use of the nominal group technique to recognize the causes of each nutrition-related health problem. A written permission was obtained to use the photograph. 
lem $\mathrm{X}$ in our region?" and they were asked to write down their responses privately.

\section{Step 2: 'Round Robin' Recording of Causes Priorities}

Each contributor was requested to express 1 cause priority at a time, and his/her idea was written on the flip chart without evaluation. Then, the round was repeated and the most critical comment was expressed each time. Thus, we could reach to the adequate numbers of ideas that responded to our research question entirely (saturation).

\section{Step 3: Clarification of Causes Priorities}

Each idea was discussed. Participants were encouraged to share their views and express their opinions about the pros and cons of each item. There was a further explanation about each item, so everyone in the group had a full understanding of the concept.

\section{Step 4: Collapse of Causes Priorities}

The facilitator organized all the listed causes priorities into "behavioral" and "nonbehavioral" groups, simplified them and identified and removed duplicates. These were written on a new flip chart and discussed with the group to ensure that all participants understood and approved of the assembled causes priorities.

\section{Step 5: Ranking of Causes Priorities}

Each participant was asked to rank the items on a card and allocated a point between 1 and 5 to each cause, with their first preference receiving 5 points and their fifth predilection earning 1 point based on 2 criteria, including the importance of the reason and the possibility of changing the purpose. The average score was calculated for each item. At this step, all items that had received a rank were listed so that all participants could observe them. The items were then ranked according to the average point. Then, 9 professionals reviewed the rankings, and agreement reached on the final list of 5 priorities of "behavioral" and "nonbehavioral" causes.

Afterward, the data correlated to nutrition-related health problems in the population of mentioned cities registered in the SIB network (an abbreviation for the Persian equivalent of "Integrated Health System" which is a comprehensive national health information system of the healthcare service delivery centers) were obtained with an official permission from the vice chancellor for health at Abadan Faculty of Medical Sciences to access the SIB network and compare it to the study results. Then, a list of nutrition-related health problems in the studied cities was prepared and matched with the findings of the present study.

\section{Method of Qualitative Analysis}

The analysis of data from the "nutrition needs assessment" phase of the study and reporting of the results were done using inductive content analysis based on the method described in Beigzadeh study (20), enabling the analysis of data collected by the worksheets and the NGT sessions. Also, we used inductive content analysis to quantitative analysis of data results from the scoring and ranking method used to conclude the completed worksheets and
NGT meetings and identify the priorities of nutritionrelated health problems and their "behavioral" and "nonbehavioral" causes derived from the data (21). Using this technique, all members of the research team listed their ideas for nutrition-related health problem and their cause, and categorized them in a "behavioral" and "nonbehavioral" format in a list. The list was then negotiated between members of the research team. This was done in an iterative process until reaching completeness and agreement on the final list. Finally, all members of the research team reviewed the categorized lists for compatibility and confirmation.

\section{Phase 2: Community Based Review of Nutrition Course} Plan

In this phase, the "General Principles of Nutrition" course plan in the medical doctorate curriculum, and "Nutrition and Nutrition Therapy" course plan in the bachelor of the nursing curriculum were reviewed. After revision, the course plan was presented to the medical $(n=124)$ and nursing (n $=128$ ) students $(51 \%$ male), with a mean age of $20.9 \pm 3.5$ years in 2 consecutive semesters (first and second semester of 2018-2019 the academic year) through lectures, question and answer sessions, group discussions, team-based learning (TBL), and virtual teaching in 17 sessions.

\section{Results}

\section{Nominal Group Technique (NGT)}

The final ranking of each nutrition-related health problems priority in Abadan, Khorramshahr, and Shadegan from the training need assessment was recognized based on the mean scores obtained by the survey. The top 5 priorities identified in Abadan were obesity in adults; hypertension, overweight, obesity, and anemia in pregnant women; type 2 diabetes mellitus and vitamin D deficiency in adults; nonalcoholic fatty liver diseases; and overweight and obesity in children, respectively. Also, the top 5 priorities recognized in Khorramshahr were type 2. diabetes mellitus, increased consumption of high-carbohydrate and fast foods, vitamin D deficiency, overweight and obesity with an emphasis on abdominal obesity; and hypertension, respectively. Moreover, the top 5 priorities documented in Shadegan were anemia in pregnant women and type 2 diabetes mellitus in adults; incorrect dietary pattern and inappropriate food habits; severe wasting in children aged 5 to 12 years; overweight and obesity in pregnant women and hypertension; and osteoporosis. It is necessary to explain that the nutrition-related health problems with the same score obtained the same priority in the TNA phase.

The Matching of the TNA Finding With the Databases of Iranian Deputy Minister of Health and Medical Education

To match the data correlated to nutrition-related health problems priority obtained from TNA phase of the study with the databases of the Deputy Minister of Health and Medical Education, we extracted the 5 nutrition-related health problem's priorities recorded in SIB network, with the highest percentage of prevalence among the total population who were under primary health care separate- 
ly for Abadan (Table 1), Khorramshahr (Table 2), and Shadegan (Table 3) and matched them with the findings of the present study. The results showed close similarities between the data extracted from the present study and the information obtained from the SIB network in terms of 5 recorded nutrition-related health problem's priorities. Thus, in Abadan, obesity in adults was the first priority of nutrition-related health problems of present study and the second priority of the nutrition-related health problem's priorities recorded in SIB network.

Also, in Khorramshahr, an increased consumption of high-carbohydrate and fast foods was the second nutrition-related health problem's priorities of the present study but it was the third one in the database recorded in the SIB network. However, in Shadegan, type 2 diabetes mellitus was found as the first priority of nutrition-related health problems in the present study but it was the fourth priority in the database recorded in the SIB network.

Moreover, 5 priorities of the recorded nutrition-related health problems in the whole population covered by the Deputy of Health of Abadan Faculty of Medical Sciences were obesity in adults (69\%), vitamin D deficiency in adults $(68 \%)$, overweight and obesity in pregnant women $(57 \%)$, hypertension $(26 \%)$, and anemia in pregnant women $(23 \%)$.

\section{Identification of Causes for Nutrition-Related Health Problems by NGT}

In the present study, NGT was selected as a highly structured technique and a democratic process to form a set of collective priorities of "behavioral" and "nonbehavioral" causes for each nutrition-related health problem according to a scoring system by 2 criteria. NGT allows for the sharing of ideas from groups of professionals who had insight into health and nutrition care, which were then discussed and ranked by the group, producing consensus decisions (19).

In terms of definition, behavioral causes were defined as causes that could be corrected by nutrition education, and nonbehavioral causes were defined as causes that could not be corrected by nutrition education.

Tables 4 to 8 show the prioritizations of behavioral and nonbehavioral causes of each priority of nutrition-related health problems in the whole region (Abadan, Khorramshahr, and Shadegan). Participants were asked to identify 5 behavioral and nonbehavioral causes of nutrition-related health problems by NGT. However, regarding the nonbehavioral causes of overweight and obesity in children, participants were unable to extract more than 2 nonbehavioral causes. Also, in the case of nonalcoholic fatty liver diseases (NAFLD), the participants extracted 4 behavioral and 3 nonbehavioral causes. Also, in the NGT process, the causes with the same score in step 5 obtained the same rank in the ranking of priorities.

\section{Review of Nutrition Course Plan}

In the second phase, the results of the first phase of the study were applied for the review of medical and nursing nutrition course plans. In the doctorate of medicine's nutrition course plane: (1) the section "understanding the common nutrition-related health problems in the community and

Table 1. Nutrition-related Health Problems Priorities in Abadan According to the Study Results and Databases of the: Iranian Deputy Minister of Health and Medical Education

\begin{tabular}{|c|c|c|}
\hline Priority Rank & Study Results & Databases \\
\hline 1 & Obesity in adults & Vitamin D deficiency in adults $(68 \%)^{*}$ \\
\hline 2 & Hypertension, overweight, obesity, and anemia in pregnant women; & Obesity in adults $(67 \%)^{*}$ \\
\hline 3 & Type 2 diabetes mellitus and vitamin D deficiency in adults & Overweight and obesity in pregnant women $(40 \%)^{*}$ \\
\hline 5 & Overweight and obesity in children & Type 2 diabetes mellitus $(14 \%)^{*}$ \\
\hline
\end{tabular}

Table 2. Nutrition-related Health Problems Priorities in Khorramshahr According to the Study Results and Databases of the Iranian Deputy Minister of Health and Medical Education

\begin{tabular}{|c|c|c|}
\hline Priority Rank & Study Results & $\begin{array}{l}\text { Databases of the Iramian Deputy Minister of Health and } \\
\text { Medical Education }\end{array}$ \\
\hline 1 & Type 2 diabetes mellitus & Vitamin D deficiency $(68 \%)^{*}$ \\
\hline 2 & Increased consumption of high-carbohydrate and fast foods & Overweight and obesity in adults $(66 \%)^{*}$ \\
\hline 4 & Overweight and obesity with an emphasis on abdominal obesity & Hypertension $(26 \%) *$ \\
\hline 5 & Hypertension & Type 2 diabetes mellitus in adults $(14 \%) *$ \\
\hline
\end{tabular}

Table 3. Nutrition-Related Health Problems Priorities in Shadegan According to the Study Results and Databases of the Iranian Deputy Minister of Health and Medical Education

\begin{tabular}{|c|c|c|}
\hline Priority Rank & Study Results & $\begin{array}{l}\text { Databases of the Iranian Deputy Minister of Health and } \\
\text { Me:dical Education }\end{array}$ \\
\hline 1 & Anemia in pregnant women and type 2 diabetes mellitus in adults & Vitamin D deficiency in adults $(68 \%)^{*}$ \\
\hline 2 & Incorrect dietary pattern and inappropriate food habits & Hypiertension $(26 \%)^{*}$ \\
\hline 4 & Overweight and obesity in pregnant women and hypertension & Type 2 diabetes mellitus in adults $(14 \%)^{*}$ \\
\hline 5 & Osteoporosis & Severe wasting in children aged 5 to 12 years $(13 \%)^{*}$ \\
\hline
\end{tabular}


Table 4. The Prioritization of Behavioral and Nonbehavioral Causes of Prioritized Nutritional-Related Health Problem: Obesity in Adults*

\begin{tabular}{|c|c|c|}
\hline Type of Cause & Rank & Cause \\
\hline \multirow{5}{*}{ Behavioral } & 1 & Snacking \\
\hline & 2 & Wrong eating habits, low physical activity, irregular sleeping and waking hours \\
\hline & 3 & Insufficient nutrition knowledge \\
\hline & 4 & Wrong cooking method, advertising \\
\hline & 5 & Nervous overeating \\
\hline \multirow{5}{*}{ Nonbehavioral } & 1 & Using technology \\
\hline & 2 & Easy and convenient access to restaurants \\
\hline & 3 & Secondary obesity caused by diseases \\
\hline & 4 & Bad weather \\
\hline & 5 & Residence in the apartment \\
\hline \multicolumn{3}{|c|}{$\begin{array}{l}\text { *Two criteria, including the importance of the cause and possibility of changing the cause were used to prioritize the causes of problems; behavioral causes were defined as } \\
\text { causes that could be corrected by nutrition education; and nonbehavioral causes were defined as causes that could not be corrected by nutrition education. }\end{array}$} \\
\hline \multicolumn{3}{|c|}{$\begin{array}{l}\text { Table 5. The Prioritization of Behavioral and Nonbehavioral Causes of Prioritized Nutritional-Related Health Problem: Hypertension, Overweight, } \\
\text { Obesity, and Anemia in Pregnant Women }\end{array}$} \\
\hline Type of Cause & Rank & Cause \\
\hline \multirow{8}{*}{ Behavioral } & 1 & -Incorrect education \\
\hline & & -Sedentary lifestyle \\
\hline & & -Misconceptions \\
\hline & 2 & -Poor nutritional patterns \\
\hline & 3 & Short intervals between pregnancies \\
\hline & 4 & -Irregular consumption of dietary supplements \\
\hline & & -Low consumption of iron-rich foods such as legumes \\
\hline & 5 & Inadequate disease care \\
\hline \multirow{6}{*}{ Nonbehavioral } & 1 & Genetic diseases \\
\hline & 2 & Pre-pregnancy obesity \\
\hline & 3 & -Short interval between pregnancies \\
\hline & & -family dimension \\
\hline & 4 & Pre-pregnancy anemia \\
\hline & 5 & Multiplication \\
\hline
\end{tabular}

*Two criteria including the importance of the cause and possibility of changing the cause were used to prioritize the causes of problems; behavioral causes were defined as causes that could be corrected by nutrition education; and nonbehavioral causes were defined as causes that could not be corrected by nutrition education.

Table 6. The Prioritization of Behavioral and Nonbehavioral Causes of Prioritized Nutritional-Related Health Problems: Type 2 Diabetes Mellitus, and Vitamin D Deficiency in Adults*

\begin{tabular}{|c|c|c|c|}
\hline & Rank & Type 2 Diabetes Mellitus & Vitamin D Deficiency \\
\hline \multirow[t]{7}{*}{ Type of Cause } & & Cause & Cause \\
\hline & 1 & -Sedentary lifestyle (not exercising for at least 30 & -Insufficient exposure to sunlight \\
\hline & & minutes a day) & -Insufficient taking of vitamin D supplement \\
\hline & & -High calorie intake in compared to energy requirement & \\
\hline & & -Tending to consume fast foods & -Inadequate education about how and how much \\
\hline & 2 & -Limited consumption of fruits and vegetables & expiosure to sunlight \\
\hline & & -High sugar intake & $\begin{array}{l}\text { - Unpleasant taste of vitamin D supplements } \\
\text { - Limited consumption of dairy products }\end{array}$ \\
\hline \multirow{8}{*}{ Behavioral } & 3 & -Low perceived sensitivity to diabetes & Limited use of micronutrient sources \\
\hline & 4 & -Inability to control environmental and psychological & -Clothing \\
\hline & & stress & -Using sunscreen \\
\hline & & -Limited intake of fatty fish & \\
\hline & & -Limited consumption of legumes & \\
\hline & 5 & Limited consumption of whole grain breads & $\begin{array}{l}\text { Tendency to traditional medicine and its misin- } \\
\text { formation about vitamin D intake }\end{array}$ \\
\hline & 1 & Obesity and insulin resistance & $\begin{array}{l}\text { Inadequate accessi to foods fortified with vitamin } \\
\text { D }\end{array}$ \\
\hline & 2 & $\begin{array}{l}\text {-Positive family history and genetics } \\
\text {-Use of technology }\end{array}$ & $\begin{array}{l}\text { Lactose and gluten intolerance and lack of ac- } \\
\text { cess to their special milks }\end{array}$ \\
\hline \multirow[t]{3}{*}{ Nonbehavioral } & 3 & Gestational diabetese mellitus (GDM) & High prevalence of kidney disease \\
\hline & 4 & Apartment lifestyle & \\
\hline & 5 & $\begin{array}{c}\text {-Bad weather and the resulting sedentary lifestyle, } \\
\text { - Polycystic ovary syndrome (PCOS) } \\
\text { - Lack of covered parks }\end{array}$ & \\
\hline
\end{tabular}

their behavioral and nonbehavioral causes," was added (2). disease, nutritional anemia (with an emphasis on the gestaThe "diseases caused by malnutrition" section was changed tional anemia), prevention, diagnosis, and treatment of vitto "the spectrum of malnutrition from underweight to over- amin D deficiency." In the baccalaureate of nursing's nutriweight and obesity in children and adults, obesity-related tion course plan: (1) sections "understanding the common complications such as diabetes and nonalcoholic fatty liver nutrition-related health problems in the community and 
Table 7. The Prioritization of Behavioral and Nonbehavioral Causes of Prioritized Nutritional-Related Health Problems: Nonalcoholic Fatty Liver Diseases (NAFLD) ${ }^{*}$

\begin{tabular}{|c|c|c|}
\hline Type of Cause & Rank & Cause \\
\hline \multirow{7}{*}{ Behavioral } & 1 & -High calories diet \\
\hline & & -High body mass index (BMI) \\
\hline & & -Consume sausages \\
\hline & 2 & -Limited consumption of fruits and vegetables \\
\hline & 3 & -Tendency to fall asleep immediately after eating \\
\hline & & - Low selenium intake \\
\hline & 4 & Taking high portion size \\
\hline \multirow{3}{*}{ Nonbehavioral } & 1 & Type 2 diabetes mellitus \\
\hline & 2 & -Toxins and occupational pollutants \\
\hline & 3 & -Pregnancy \\
\hline \multicolumn{3}{|c|}{$\begin{array}{l}\text { *Two criteria including the importance of the cause and possibility of changing the cause were used to prioritize the causes of problems; behavioral } \\
\text { causes were defined as causes that could be corrected by nutrition education; and nonbehavioral causes were defined as causes that could not be } \\
\text { corrected by nutrition education. }\end{array}$} \\
\hline \multicolumn{3}{|c|}{$\begin{array}{l}\text { Table 8. The Prioritization of Behavioral and Nonbehavioral Causes of Prioritized Nutritional-Related Health Probilems: Overweight and Obesity i } \\
\text { Children }\end{array}$} \\
\hline Type of Cause & Rank & Cause \\
\hline \multirow{10}{*}{ Behavioral } & 1 & - High carbohydrate diet due to high availability \\
\hline & & $\begin{array}{l}\text { - Sedentary lifestyle due to the change in children's play pattern from actiwe games to sedentary games } \\
\text {-Consumption of high-calorie - high-fat foods (like junk food, etc.) }\end{array}$ \\
\hline & 2 & - Incorrect eating behaviors at school lunch and school buffet \\
\hline & 3 & $\begin{array}{l}\text { - Incorrect eating behaviors among family and not spending time and money on the child's physical activity } \\
\text { - Advances in technology and its use by children }\end{array}$ \\
\hline & 4 & - Cultural tendencies towards obesity \\
\hline & & - Computer games and the resulting reduced physical activity \\
\hline & & $\begin{array}{c}\text { - Tendency to consume dry milk instead of breast milk } \\
\text { - Microphagy }\end{array}$ \\
\hline & 5 & - Consume high-fat local milk \\
\hline & & - Eliminate breakfast \\
\hline & & 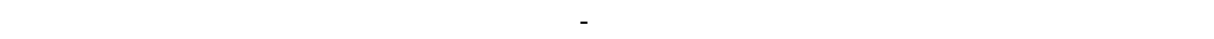 \\
\hline \multirow{4}{*}{ Nonbehavioral } & 1 & - Genetic obesity (both parents) \\
\hline & & - Inappropriate advertising \\
\hline & & - Wrong policies \\
\hline & 2 & Obesity caused by diseases such as hypothyroidism \\
\hline
\end{tabular}

*Two criteria including the importance of the cause and possibility of changing the cause were used to prioritize the causes of problems; behavioral causes were defined as causes that could be corrected by nutrition education; and nonbehavioral causes were defined as causes that could not be corrected by nutrition education.

their behavioral and nonbehavioral causes" and (2) the section "nutrition therapy for obesity in children and adults, nonalcoholic fatty liver disease and kidney disease" were added. Nutrition and nursing departments of Abadan Faculty of Medical Sciences approved the revised nutrition course plans for implementation.

\section{Discussion}

The general aim of this study was a community-based educational need assessment designed to review the nutrition course plan in the doctorate of medicine and baccalaureate of nursing. The results demonstrated the nutrition-related health problems observed in 3 cities covered by Abadan Faculty of Medical Sciences as the society's needs. Also, we compared the results obtained from this study with the databases of the Deputy Minister of Health and Medical Education and found close similarities between the results of the present study and the information extracted from SIB network in terms of 5 recorded nutrition-related health problems priorities.

Moreover, NGT determined the behavior and nonbehavioral causes of nutrition-related health problems priorities. The extracted society's needs were used for the community- based review of nutrition course plans. Obesity in adults, type 2 diabetes mellitus, and gestational anemia were the first nutrition-related health problems priorities in the investigated community. Also, wrong cooking method, snacking, and eating habits, as well as inadequate nutrition knowledge were found to be the most critical behavioral causes of obesity in the target community.

As we know, obesity and diabetes are concerning medical conditions from which people suffer and die from every day (22). Primary care physicians (PCP) must be organized to treat a variety of nutrition-related health problems, such as diabetes and obesity, with nutrition recommendation (23). The aim of upgrading medical education is to train health care professionals to provide better health care and reach better health and quality of life for the community (18). Like every other science, appllying the best evidence from health-related problems in main concern areas leads to improving the quality and strength of medical education (24). Meanwhile, nutrition science has developed rapidly over the past 50 years. In an era that requires the practice of evidence-based medicine, there is convincing evidence that lifestyle practices, including mutrition behaviors, influence health, and disease, reflect a need for evidence-based and 
outcome-focused education (25). Accordingly, the results of our study provided sufficient evidence to review the nutrition course plan of medical and nursing students which is used in their nutrition education. This evidence emphasized the importance of focusing on noncommunicable diseases for a community-based review of a nutrition course plan. Our results are in line with inductive ongoing programs around the world to enhance and improve nutrition education and knowledge of health care professionals which have focused on noncommunicable and chronic disease prevention from a nutrition perspective. Nutrition education review groups in the United Kingdom and the United State have been developed to increase awareness among medi$\mathrm{cal} /$ health care professionals concerning the importance of clinical and public health nutrition in the prevention of noncommunicable diseases (25). Moreover, we found insufficient nutrition knowledge and improper eating habits as the most critical behavioral causes of noncommunicable diseases in the community. Since the provision of nutrition care by clinicians is important in promoting healthy dietary habits, it is important to consider strategies for improving eating habits of the community in the reviewing of nutrition curse planes, including promoting the nutritional awareness of medical and nursing students and teaching communitybased nutrition education methods. However, according to qualitative studies, medical students and physicians have reported inadequate nutrition education and preparation during their training at universities due to a lack of priority for nutrition education and poor collaboration with nutrition professionals (8). Exploring the priorities of nutritionrelated health problems with the help of nutrition professionals to review the course plan can also help to improve the collaboration of physicians and nutrition professionals, which in itself is effective in promoting nutrition education to students.

On the other hand, many reports have highlighted the need to review medical education to align it with community's needs (9). However, disadvantageously, allocated hours in which the medical training may emphasize behavioral, social, and epidemiological sciences have been reduced (26). In the present study, we tried to reveal how can the educators extract the priorities of nutrition-related health problems as the society's needs with the help of professionals and use the extracted needs for community-based review of nutrition course plane of medical and nursing students. The inclusion of new subjects, including obesity in adults, type 2 diabetes mellitus, and gestational anemia as the community's needs in the nutrition course plans of medical and nursing students may improve the awareness of the medical community about social needs. They can also be accomplished by understanding the fundamental determinants of disease, such as behavior and nonbehavioral elements affecting patients' health and quality of life.

Our study is one of the few studies to determine the educational needs with a community-oriented approach with an aim to revise the nutrition education for medical sciences students (7, 27-29). Other studies have focused on the improvement of community nutrition education rather than student nutrition education.

The literature review showed that from 1996 to 2013 a to- tal of 3 articles have been published. These papers were in the fields of geriatric nutrition training curriculum for nutrition/dietetics programs (7), essentials of nutrition education in medical schools (27), and the need to revise the nutrition curriculum for nutrition students (28). A significant reform in undergraduate medical education curriculum provides a new motivation and a novel opportunity to develop medical nutrition education and training nationwide (29).

This is the first study to qualitatively explore the community's needs designed to the community-based review of the nutrition course plan for medical and nursing students. However, the limitation of the present study was that the data were collected from Abadan Faculty of Medical Sciences, and thus might not be representative of all Iranian communities. However, as we know, in a qualitative study, the results cannot be generalized to other situations and people (30).

\section{Conclusion}

This paper demonstrated the possibility of using the nutritional need assessment by NGT to propose a communitybased review of nutrition course plans for medical and nursing students in Southwest of Iran. This was the first phase in the development of a community-based nutrition course plan to focus on nutrition-related health problems in the community, which is most needed in education. The next step is to translate the nutrition-related health problems priorities into a community based revised course plan by setting up the implementation for medical and nursing students and evaluating the new course plans, including the analysis of student feedback and exam performance in future studies.

\section{Acknowledgement}

We would like to thank all staff members of Abadan Faculty of Medical Sciences working in the office of Deputy of Health and Education as well as medical and nursing students who participated in the study.

\section{Conflict of Interests}

The authors declare that they have no competing interests.

\section{References}

1. Needs Assessment Information Wants determine needs. In: Amazon; 2019.

2. Fulgham SM, Shaughnessy MF. Q and A with Ed Tech Leaders: Interview with Roger Kaufman. Educ Technol. 2008;48(5):49-52.

3. Brown J. Training needs assessment: A must for developing an effective training program. Public Pesrs Manag. 2002;31:569-578.

4. Mirzabeigi A. Course planning and course plans in formal education and human resource training. 1nd eid. Yastaroon Publishing. 2005 [In persion].

5. Miller JA, Osinski, DM. Training needs assessment. SHRM White Paper; [1996, 2002]. Available from: www.shrm.org/Research/Articles/Articles/Pages/CMS_000445.aspx.

6. Hampton C. Assessing Community Needs and Resources. In Community Tool Box. The University of Kansas, U.S; 2014. Available from: https://ctb.ku.edu/en/table--of-contents/assessment/assessingcommunity-needs-and-resources/conduct-concerns-surveys/main

7. Knutson BJ, Gehling EM. Gerontology Training needs for Nutrition/Dietetics Students: Results of a needs Assessment. J Am Diet Assoc. 1996;96:A82.

8. Mogre V, Stevens FCJ, Aryee PA, Amalba A, Scherpbier A. Why nutrition education is inadequate in the medical curriculum: a 
qualitative study of students' perspectives on barriers and strategies. BMC Med Educ. 2018;18(1):26.

9. Maudsley RF. Content in context: medical education and society's needs. Acad Med. 1999;74:143-145.

10. CoNiME NRCUS: Nutrition Education in U.S. Medical Schools. Washington, DC 1985.

11. Adams KM, Kohlmeier M, Powell M, Zeisel SH. Nutrition in medicine: nutrition education for medical students and residents. Nutr Clin Pract. 2010;25:471-480.

12. Delegge MH, Alger-Mayer S, Van Way 3rd CW, Gramlich L. Specialty residency training in medical nutrition education: history and proposal for improvement. J Parenter Enteral Nutr. 2010;34:47S-56S.

13. Lenders CM, Deen DD, Bistrian B, Edwards MS, Seidner DL, McMahon MM, et al. Residency and specialties training in nutrition: a call for action. Am J Clin Nutr. 2014;99:1174S-1183S.

14. Shamsi Gooshki E, Pourabbasi A, Akbari H, Rezaei N, Arab Kheradmand A, Kheiry Z, et al. Internationalization of medical education in Iran: A way towards implementation of the plans of development and innovation in medical education. J Adv Med Educ Prof. 20186:43-48..

15. Vasileiou K, Barnett J, Thorpe S, Young T. Characterising and justifying sample size sufficiency in interview-based studies: systematic analysis of qualitative health research over a 15-year period. BMC Med Res Methodol. 2018;18:148.

16. The Role of Nutrition in Maintaining Health in the Nation's Elderly: Evaluating Coverage of Nutrition Services for the Medicare Population. edn. National Academies Press (US) Washington DC 2000.

17. Holakouie Naieni K, Ahmadvand A, Ahmadnezhad E, Alami A. A community assessment model appropriate for the Iranian community. Iran J Public Health. 2014:43:323-330.

18. Amini M, Kojuri J, Lotfi F, Karimian Z, Abadi AS. Research priorities in medical education in the Eastern Mediterranean Region. East Mediterr Health J. 2012;18:687-692.

19. Tuffrey-Wijne I, Wicki M, Heslop P, McCarron M, Todd S, Oliver D, et al. Developing research priorities for palliative care of people with intellectual disabilities in Europe: a consultation process using nominal group technique. BMC Palliat Care. 2016;15:36.

20. Beigzadeh A, Adibi P, Bahaadinbeigy K, Yamani N. Strategies for teaching in clinical rounds: A systematic review of the literature. J Res Med Sci. 2019;24:33.

21. Potter M GS, Hamer v. The Nominal Group Technique: A useful consensus methodology in physiotherapy research. NZ J Physiother. 2004;32(2):70-75.

22. Bidlack WR. Interrelationships of food, nutrition, diet and health: the National Association of State Universities and Land Grant Colleges White Paper. J Am Coll Nutr. 1996;15:422-433.

20. Van weel C. Morbidity in family medicine: the potential for individual nutritional counseling, an analysis from the Nijmegen Continuous Morbidity Registration. Am J Clin Nutr. 1997;65:1928S$1932 \mathrm{~S}$.

24. Mostafavi E HA, Siavashi M, Ranjbar H, Fasihi Harandi M. Updating the curriculum of Ph.D by research training courses in medical sciences in Iran. Iran J Strides Dev Med Educ. 2013;10:358-368.

25. Kris-Etherton PM, Akabas SR, Bales CW, Bistrian B, Braun L, Edwards MS, et al. The need to advance nutrition education in the training of health care professionals and recommended research to evaluate implementation and effectiveness. Am J Clin Nutr. 2014;99:1153S-1166S.

26. Schulman J. Nutrition Education in Medical Schools: Trends and Implications for Health Educators. Med Educ Online. 1999;4(1):4307.

27. Essentials of nutrition education in medical schools: a national consensus. American Medical Student Association's Nutrition Curriculum Project. Acad Med. 1996;71:969-971.

28. Sadeghi-ghotabadi F, Shakibazadeh E, Omidvar N, Mortazavi F. Educational Needs Assessment of Nutrition Experts Working in Iranian Health System. Iran J Nutr Sci Food Technol. 2013;8:111-101. [In Persion]

29. Aspry KE, Van Horn L, Carson JAS, Wylie-Rosett J, Kushner RF, Lichtenstein AH, et al. Medical Nutrition Education, Training, and Competencies to Advance Guideline-Based Diet Counseling by Physicians: A Science Advisory From the American Heart Association. Circulation. 2018;137:e821-e841.

30. Gardeshi Z, Amini M, Nabeiei P. The perception of hidden curriculum among undergraduate medical students: a qualitative study. BMC Res Notes. 2018;11:271. 